\title{
ESCUTANDO $\odot$ BRINCAR NUM AMBULATÓRIO DE VIOLÊNCIA SEXUAL INFANTIL
}

Miriam Tachibana

Universidade Federal de Uberlândia

Paula Carvalho Barbosa

Universidade Federal de Uberlândia
Recebido em: 12/02/2020

$1^{\text {a }}$ revisão em: 23/02/2021

$2^{\mathrm{a}}$ revisão em: 01/04/2021

Aceito em: 10/05/2021

\section{RESUMO}

Considerando a preocupação dos profissionais que compõem a rede de proteção no sentido de evitar a vitimização secundária da criança que sofreu violência sexual, tem sido debatido qual seria o melhor meio de obter o seu depoimento de forma minimamente invasiva. Este trabalho teve o objetivo de apresentar um relato de experiência em um ambulatório, situado no interior de Minas Gerais, no qual é realizada a escuta especializada. A partir da narrativa de um caso clínico, são feitas considerações acerca: 1) do uso de estratégias lúdicas como forma de favorecer a comunicação emocional da criança, bem como de fortalecê-la psiquicamente; 2) da importância da escuta sensível dos sentimentos ambivalentes que a criança pode apresentar frente ao agressor, mesmo após ter declarado a violência a qual foi submetida. Espera-se, a partir deste relato de experiência, enriquecer a discussão sobre alternativas de escuta dessa população vulnerável.

Palavras-chave: abuso sexual; escuta psicanalítica; violência doméstica. 


\section{LISTENING TO THE PLAY IN A CHILD SEXUAL VIOLENCE OUTPATIENT CLINIC}

\section{ABSTRACT}

Considering the concern of the professionals who join the protection network to avoid secondary victimization of children who have suffered sexual violence, the best way to obtain their testimony in a minimally invasive manner has been debated. This paper aimed to present an experience report of a specialized outpatient clinic, located in the countryside of Minas Gerais, where specialized listening is carried out. Based on the narrative of a clinical case, considerations are highlighted about: 1) the use of playful strategies as a way of favoring the emotional communication of the child, as well as strengthening the child psychically; 2) the importance of sensitive listening to the ambivalent feelings that the child may have towards the aggressor, even after declaring the violence to which she was subjected. This experience report is expected to enrich the discussion about listening alternatives for this vulnerable population.

Keywords: sexual abuse; psychoanalytic listening; domestic violence.

\section{ESCUCHANDO EL JUEGO EN UNA CLÍNICA AMBULATORIA DE VIOLENCIA SEXUAL INFANTIL}

\section{RESUMEN}

Teniendo en cuenta la preocupación de los profesionales de la red de protección en evitar la victimización secundaria de los niños que han sufrido violencia sexual, se ha debatido la mejor manera de obtener su testimonio de forma mínimamente invasiva. El objetivo de este estudio fue presentar un informe de experiencia en un ambulatorio especializado ubicado en Minas Gerais, donde se realiza la escucha especializada. A partir de la narración de un caso clínico, se hacen consideraciones sobre: 1) el uso de estrategias lúdicas como forma de favorecer la comunicación emocional del niño, así como de fortalecerlo psíquicamente; 2) la importancia de la escucha sensible a los sentimientos ambivalentes de lo niño hacia el agresor, incluso después de declarar la violencia a la que fue sometido. Se espera, a partir de este informe de experiencia, enriquecer la discusión sobre las alternativas de escucha para esta población vulnerable.

Palabras clave: abuso sexual; escucha psicoanalítica; violencia doméstica. 


\section{INTRODUÇÃO}

A violência sexual infantil, que, segundo o Sistema de Informação de Proteção para a Infância e Adolescência (SIPIA), tem sido em sua maioria perpetrada no ambiente intrafamiliar, não é um fenômeno novo. Entretanto, no Brasil, ela passou a receber maior atenção apenas mais recentemente, em especial a partir da década de 90, com a promulgação do Estatuto da Criança e do Adolescente (ECA), prevendo mecanismos de proteção e de garantia de direito às vítimas (Mendes, 2019), gerando um impacto nos diferentes serviços brasileiros, que tiveram que ser revisitados e levados a formarem uma parceria dialógica entre si.

Um exemplo disso é que os profissionais da área de saúde foram convocados a não mais se limitarem aos cuidados dos danos da violência, devendo obrigatoriamente notificar tais casos aos órgãos competentes, estando passíveis de penalização se não o fizerem (Cezar, Arpini, \& Goetz, 2017). Nota-se, contudo, que os profissionais da saúde sentem-se despreparados para realizar a referida notificação, seja porque têm medo do suposto agressor, seja porque entendem que a melhor medida consistiria em encaminhar para um serviço especializado que se encarregaria da notificação, ou também por compreenderem a notificação como um ato jurídico que não Ihes caberia, dentre outros (Veloso, Magalhães, \& Cabral, 2017).

Observa-se que não apenas a notificação suscita questionamentos por parte dos profissionais da saúde, como também outros momentos componentes deste longo caminho percorrido pela criança, uma vez inserida na rede de proteção. No presente trabalho, pretende-se centrar num momento específico, que tem despertado dúvidas e reflexões nos diferentes profissionais que compõem a rede de proteção: o da escuta especializada, quando a criança apresenta o seu depoimento da violência sexual sofrida.

A escuta especializada, assim como o depoimento especial, equivale a uma modalidade de escuta à criança ou ao adolescente vítima de violência sexual, prevista na Lei $n^{\circ} 13.431 / 2017$. A escuta especializada é o procedimento de entrevista sobre a situação de violência com criança ou adolescente perante órgão da rede de proteção, sem um protocolo rígido tal como no caso do depoimento especial. O depoimento especial, anteriormente intitulado depoimento sem dano, consiste na oitiva da criança, realizada numa sala privativa, porém munida de câmeras e de microfones, em que estão presentes apenas a criança que vai depor e o técnico que a entrevistará. Este, por sua vez, faz uso de um ponto eletrônico como via de comunicação com outros profissionais que se encontram numa sala de audiência e que acompanham por vídeo o que se passa no depoimento especial. A despeito de não haver uma indicação formal de qual seria a formação do técnico, dada à compreensão de que o fenômeno da violência sexual infantil não se limita a uma categoria científica/profissional, são os profissionais da Psicologia e do Serviço Social que têm sido solicitados a cumprir essa função (Mendes, 2019). 
Ambas as modalidades de escuta foram instituídas essencialmente por dois motivos. Um deles relaciona-se à preocupação em obter de modo preciso o depoimento da criança, uma vez que, como geralmente nos casos de violência sexual infantil faltam evidências físicas que constituiriam a prova por excelência do que ocorreu, o depoimento da vítima torna-se a única prova, de sorte que ela deixa de ser vista exclusivamente como vítima e se torna testemunha chave da acusação (Benia, 2015). Todavia, faz-se necessário que essa escuta seja realizada de modo cuidadoso, uma vez que têm sido frequentes os casos de denúncia cujos processos nas Varas de Família ou Criminais demandam uma investigação para averiguar se se trata de fato de um caso de violência sexual ou se de alienação parental (Oliveira \& Russo, 2017). Haveria ainda casos de falso positivo, em que a criança relataria uma violência sexual não ocorrida, em função da maneira pela qual a entrevista foi conduzida, uma vez que falsas memórias podem ser produzidas frente a perguntas sugestivas (Henriques \& Pompeu, 2020).

Outro motivo relaciona-se à preocupação em encontrar um meio mais sensível de entrevistar a criança, tendo em vista a constatação de que as delegacias e as salas de audiência traziam problemas para a realização dessa escuta da criança. Assim, a escuta especializada e o depoimento especial equivaleriam a tentativas para evitar que a criança sofresse uma vitimização secundária, que não raro vinha sendo produzida pelas próprias instituições responsáveis por seu cuidado, através de reiterados inquéritos, excessivos exames e perícias, dentre outros, caracterizando violência institucional (Mendes, 2019).

Embora seja um consenso entre os diferentes profissionais que integram a rede de proteção a importância de se desenvolver um meio para a produção de prova aliado à proteção integral da criança, nota-se que, na prática, essa parceria entre os diferentes saberes tem sido permeada de tensões. Não raro, os operadores do Direito apresentam dúvidas acerca dos fundamentos teórico-metodológicos que sustentam a prática dos profissionais da Psicologia, suspeitando, por exemplo, que o brincar durante a escuta - seja na escuta especializada, seja no depoimento especial -, seria um elemento que mais distrairia a criança do que um recurso a favor do depoimento (Benia, 2015). De maneira análoga, frequentemente os profissionais da Psicologia sentem que estão sendo forçados a apurar a verdade dos fatos, substituindo os operadores do Direito, enquanto o seu objetivo primeiro é o de ofertar cuidado (Gomes, 2018).

Mediante essa discussão fervorosa sobre qual seria a melhor estratégia para obter o depoimento da criança vítima de violência sexual, assegurando a sua proteção, conforme prevê o ECA (Mendes, 2019), no presente trabalho, será apresentado um relato de experiência, junto a uma criança vítima de violência sexual, atendida em um ambulatório de escuta especializada.

\section{MÉTODO}


No referido ambulatório especializado em violência sexual, situado no interior de Minas Gerais, casos de suspeita e de confirmação de violência sexual são atendidos por uma equipe interdisciplinar, da qual as autoras fazem parte, e que é composta por profissionais e alunos da graduação e da pós-graduação da Medicina, Enfermagem, Serviço Social, Direito e Psicologia. No atendimento prestado no ambulatório, é realizada a escuta especializada, de modo que, ao mesmo tempo em que se objetiva ofertar cuidado à criança vitimizada, também é colhido o seu depoimento sobre a violência sofrida, sem o qual alguns processos jurídicos podem ficar sem andamento.

Neste ambulatório, existe um protocolo interno de atendimento no qual, inicialmente, a criança e o seu responsável são atendidos conjuntamente, por pelo menos dois integrantes da equipe interdisciplinar. Após um breve período de apresentação, havendo o consentimento da criança e de seu responsável, é promovida uma escuta separada da criança. Assim, enquanto seu cuidador permanece na sala de atendimento com um dos integrantes da equipe, a criança é convidada para ir com algum membro da equipe de Psicologia para outra sala no mesmo ambulatório, na qual é realizada a escuta especializada.

A sala em que a escuta é realizada é capacitada de brinquedos variados, dada a compreensão, por parte da equipe de Psicologia, de que o brincar seria o meio por excelência para a criança se comunicar significativamente. Trata-se de um pressuposto discutido por diferentes teóricos da Psicanálise, em especial pelo psicanalista inglês Donald Winnicott, que, a despeito de não ter teorizado sobre o brincar com crianças vítimas de violência sexual, deixou uma obra robusta sobre a importância do brincar, independentemente de qual questão estaria atravessando a criança. Para Winnicott (1971/1975), o brincar apresentaria duas vantagens: 1) a criação de um ambiente lúdico, que por si só já faria com que a criança se sentisse mais relaxada, permitindo que ela entrasse em contato com aspectos angustiantes que, de outra forma, talvez não fosse possível; e 2) a possibilidade de, em alguns casos, em meio ao faz-de-conta característico do brincar, a criança se sentir mais criadora e espontânea, o que poderia levá-la inclusive a resgatar o sentimento de que o ambiente pode ser confiável, aspecto esse tão valioso no caso de crianças que sofreram uma invasão ambiental radical tal como a violência sexual.

Entretanto, mais do que a adoção do brincar para a realização da escuta das crianças no ambulatório, é privilegiado o método psicanalítico, de modo que todo o tempo é adotada a regra fundamental da associação livre. Isso significa que a entrevista com a criança não é previamente organizada a partir de um roteiro de perguntas a serem feitas, muito embora o entrevistador tenha em mente a necessidade de obter informações sobre a violência sexual (como, por exemplo, o que ocorreu, quando ocorreu, onde ocorreu e quem foi o agressor). De maneira análoga, tampouco há a adoção de um roteiro acerca das brincadeiras a serem realizadas, havendo inclusive a compreensão de que, caso a criança não se interesse em brincar, esse seu movimento de recusa deve ser respeitado. Ao final de cada entrevista, a criança e o integrante da Psicologia que a escutou retornam 
para a sala de atendimento na qual se encontra o seu responsável, reintegrando a configuração inicial do atendimento.

Vale ressaltar que como a escuta é sustentada pelo brincar numa perspectiva psicanalítica, que muito valoriza a associação livre, fica difícil apresentar um protocolo único para toda e qualquer criança vítima de violência sexual. Observase, na literatura especializada, que existem vários questionamentos sobre como proceder nos casos de entrevista lúdica: deve-se perguntar diretamente sobre a violência sexual ou é melhor, como apostam Garbin, Queiroz, Rovida e Saliba (2012), não perguntar diretamente? Deve-se brincar junto com a criança ou apenas observá-la brincando, como questionam Rocha e Prado (2006)? Se o brincar da criança expressar claramente conteúdo sexual, deve-se preservar essa expressão espontânea ou intervir com questões, como indagam Giacomello e Melo (2011)?

Retomando novamente a obra winnicottiana, entende-se que a resposta para cada uma dessas questões varia de acordo com o modo como cada criança se apresenta, fazendo-se necessário que o profissional se adapte sensivelmente a cada situação. Desta forma, diante de uma criança que se mostra mais inibida, mostrando-se incapaz de se lançar nos brinquedos, talvez seja interessante que o psicólogo assuma a iniciativa e proponha um brincar, como gesto de cuidado para que a criança se sinta menos hesitante; por outro lado, se estiver com uma criança que já se mostra confortável desde o início do encontro, entende-se que não há por que o psicólogo "direcionar" o encontro, elegendo um brincar que poderia inclusive romper o movimento espontâneo da criança. Assim, metodologicamente, segue-se ao máximo a proposição de Winnicott (1965/1983) de que o objetivo clínico é o de ser capaz de ser um psicanalista que faz o mais apropriado para cada ocasião.

A seguir, será apresentada uma narrativa referente a uma das várias crianças atendidas nesse ambulatório, a quem foi atribuído o nome fictício "Lis". Embora Lis tenha sido atendida mais do que duas vezes, para o presente trabalho, foi realizado o recorte metodológico de relatar apenas as suas duas primeiras entrevistas, que foram as que serviram de base para a obtenção de seu depoimento. Destaca-se ainda que este material é parte de um conjunto maior de narrativas, que foram colhidas e analisadas no contexto de um trabalho de conclusão de curso, cujo projeto de pesquisa foi aprovado pelo Comitê de Ética de pesquisa envolvendo seres humanos (CAAE: 14576719.3.0000.5152).

\section{NARRATIVA DO CASO CLÍNICO}

Lis é uma menina de nove anos, que havia sido violentada sexualmente por seu pai, desde os cinco anos de idade. Entretanto, a prisão dele havia sido indeferida dada a ausência de depoimento da criança. Assim, Lis veio encaminhada pela delegacia com o pedido emergencial de que fosse obtido o seu depoimento. 
O início desse primeiro atendimento deu-se com mãe e filha sendo atendidas conjuntamente por uma estagiária da Psicologia, uma residente da Psicologia e uma interna da Medicina. Durante essa primeira parte, chamou a atenção o fato de Lis e de sua mãe se apresentarem falando alto, rindo bastante, como se estar ali fosse algo leve. Quando é proposto a Lis de ela ser levada até a sala de brinquedos para seguir conversando sem a sua mãe, ela aceita com entusiasmo. Assim, a estagiária, a residente de Psicologia e Lis se separam de sua mãe e da interna da Medicina. Mas, ao entrarem na sala de brinquedos, Lis diz, rindo, que não brinca há muito tempo. Quando questionada sobre o motivo, responde: "Ah, eu não gosto muito mais. E também não tem muito com quem brincar. E minha mãe doou meus brinquedos".

Nesse momento, entra outra criança na sala, acompanhada de uma psicóloga ${ }^{1}$. Lis observa bastante a criança mais nova no seu brincar. Quando a estagiária a questiona se ela sabe por que estava ali, Lis responde: "Sei, sim. Foi aquilo com meu pai... o que ele fez..., mas não posso falar disso agora. Não quero estragar a infância de uma criança com uma história tão triste. Ela é muito novinha... Mas se você quiser me levar em outro lugar, eu te conto tudo".

Embora a dupla da Psicologia pudesse aproveitar essa oportunidade dada por Lis para sair com ela, para uma outra sala, e a partir daí ouvir o seu depoimento, a estagiária apenas the disse que elas poderiam ficar ali mesmo, propondo que brincassem de criar coletivamente uma história, com cada uma inventando um pedacinho dela. Lis aceita prontamente a proposta. Pega 3 patinhos e uma galinha maior, dizendo: "Esse vai ser o Donald 1, esse o Donald 2, esse o Donald 3 e essa (apontando para a galinha) será a mamãe. O Donald 1 está triste, porque ele está doente. Pegou um resfriado e aí a mamãe foi com ele para o hospital. Agora vocês continuam a história".

Estagiária: Enquanto isso, o restante da família ficou em casa, mas o Donald 1 estava triste. Será que era só resfriado? A mamãe galinha estava preocupada...

Residente: Eles ficaram no hospital esperando o médico e a mamãe toda hora perguntava o que teria acontecido...

Lis: Já sei, já sei! Tem que pôr o pai (ela fala isso puxando um pato maior para a cena). Ele perguntou o que está acontecendo e vai dar comida para o Donald 2 e o Donald 3, enquanto o Donald 1 e a mamãe estão no hospital (ela organiza, então, os dois patinhos da casa em volta de uma mesa e simula que o pai está dando comida a eles). Tem também um primo (fala isso trazendo mais um outro boneco para a cena). Mas o Donald 1 estava com medo e com vergonha de falar para a mamãe dele o que tinha acontecido. Continua!

Estagiária: Pode continuar. Eu acho que você está com uma ideia ótima! 
Lis: Tá bom. Ele contou para a mamãe que o primo tinha feito uma maldade com ele. Daí eles voltaram para casa, a mamãe contou para o papai o que aconteceu e o papai expulsou o primo de lá (fala isso e aí movimenta o pato pai lançando com força o primo bem longe, com um tom de voz agressivo). Acho que acabou a história.

Encerrado esse brincar, a estagiária aproveita para perguntar sobre o pai da criança. Lis conta que já não tinha mais notícias dele. Explica que a mãe a havia proibido de falar ao telefone com ele, mas afirma que ela tampouco queria falar com ele. Logo em seguida, ela propõe que brinquem de telefone sem fio. Ela se diverte muito com as falhas de comunicação e, quando as três retornam para a sala de atendimento conjunto, em que sua mãe se encontrava, Lis fica pedindo o tempo todo para retornar à sala de brinquedos. A despedida se dá com o combinado de que, na semana seguinte, haveria mais brincar.

Na semana seguinte, tão logo Lis vê a estagiária de Psicologia, que dessa vez estava desacompanhada da residente, a abraça. As duas se separam novamente da mãe de Lis e se dirigem para outra sala. Assim que entram na sala, a estagiária diz que elas poderiam brincar, mas que, dessa vez, também gostaria que elas conversassem, o que ela aceita. Enquanto jogavam com um baralho de cartas, a estagiária indaga Lis se ela se lembrava do que elas haviam conversado na semana anterior. Sem parar de jogar, a criança diz: "Lembro, sim. Era sobre o que aconteceu comigo, né? Meu pai me estuprou. Sabe o que é isso, né? Estuprar".

Lis conta que não se lembrava direito, mas que achava que a violência havia se iniciado quando ela tinha cinco anos de idade. Explica detalhes da violência sexual, que ocorria aos finais de semana, quando ela ia para a casa do pai, de quem a mãe era divorciada. Complementa: "Desde março não vejo meu pai. Pai (fala em tom irônico)... Pai não faz isso. Eu vou ter que descobrir o que é pai. Eu queria que ele passasse pela mesma coisa e morresse. Eu tenho ódio demais".

Quando acaba o jogo de baralho, Lis fala para brincarem de dominó. Durante esse novo jogo, a estagiária indaga se Lis havia contado essa história a mais alguém, ao que ela responde que havia contado para todos de sua família, que haviam ficado em choque. Ela diz: "Eu também fiquei em choque e eu fico triste também. Sabe, eu finjo estar bem, mas eu não estou, não. É muito ruim e eu preciso crescer com isso".

Nesse ponto da conversa, a dupla chega num momento do jogo do dominó em que nem a estagiária e nem a criança tinham as peças necessárias para darem continuidade ao jogo. Sem querer encerrar o brincar, Lis inventa uma nova regra, para que fosse possível seguirem jogando com as peças que tinham em mãos. Quando esse jogo acaba, ela propõe que a estagiária e ela brinquem de desenhar livremente, juntas, na mesma folha de papel. Assim, elas fazem duas montanhas e um sol. Lis pede, então, que a estagiária faça uma linha dividindo o papel. Ela atende ao seu pedido e, quando lhe pergunta o motivo dessa linha, Lis apenas 
responde: "Esse é o lado bonito (fala apontando para uma das metades da folha) e esse é o lado feio (fala apontando para a outra metade)".

Em seguida, Lis escreve seu nome completo no verso da folha, mas logo risca com força o sobrenome que remete à filiação com o pai. Quando ela diz que gostaria de tirar esse sobrenome, a estagiária Ihe diz que ela poderia. A criança fica em silêncio e, em seguida, começa a fazer perguntas pessoais à estagiária, perguntando se ela gostava de seu próprio nome, sobre a cor de seu cabelo..., num movimento inverso ao que estava acontecendo até então. Entendendo que aquilo poderia ser um sinal de que talvez ela já não desse mais conta de ficar sendo indagada, a estagiária fala para elas retornarem à sala em que sua mãe se encontrava, recebendo o atendimento jurídico.

Tão logo a estagiária e Lis integram esse outro atendimento, notam que a mãe de Lis reclamava sobre o fato de a prisão de seu ex-marido ainda não ter acontecido. Lis ouve atentamente a conversa. De repente, ela começa a passar mal, dizendo que estava sentindo dor de barriga e náuseas. Ela começa a chorar e é desse jeito, chorosa, que ela se despede dessa segunda ida ao ambulatório.

\section{DISCUSSÃO}

Embora a partir da narrativa desse material clínico, seja possível realizar reflexões clínico-teóricas variadas, no presente trabalho, a discussão será centrada em dois aspectos centrais para se pensar metodologicamente sobre a escuta precisa e sensível da criança vítima de violência sexual: 1) o uso do brincar; e 2) a escuta da ambivalência afetiva.

\section{BRINCAR OU NÃO BRINCAR: EIS A QUESTÃO}

Logo no início do primeiro encontro, Lis comunica que já não gostava mais de brincar e que inclusive já não tinha mais brinquedos, o que, num primeiro momento, desperta o raciocínio de que talvez fosse o caso de não recorrer às estratégias lúdicas na entrevista com ela. É possível, contudo, num segundo momento, refletir se essa fala de Lis não estaria de alguma maneira alinhada a uma tentativa da criança de aparentar maior maturidade. É como se, diante da tragédia que estava vivenciando, Lis tentasse se defender do caos psíquico apelando para uma postura de extrema organização psíquica, em que ela aparece leve, sorrindo ao lado da mãe, mostrando-se como uma menina que já não tem mais hábitos infantis e que inclusive se preocupa com a criança menor que aparece, na sala de brinquedos, no início da primeira entrevista.

Trata-se de uma reflexão alinhada ao conceito de falso self, desenvolvido por Winnicott (1960/1983), em oposição ao conceito de verdadeiro self. A partir dessa teorização, Winnicott se referia a uma condição em que, mediante invasões ambientais, o indivíduo, defensivamente, deixa de entrar em contato com seu próprio mal-estar emocional. Nesse movimento em que ele se dissocia de si 
mesmo, dando conta de apresentar uma postura adaptada àquilo que socialmente dele seria esperado, há, por outro lado, a perda da espontaneidade e da autenticidade, tão associadas à saúde mental na obra winnicottiana. Desde essa perspectiva, seria possível levantar a dúvida: Lis não queria brincar ou não se via em condições de abandonar uma postura mais associada a uma defesa do tipo falso self?

Foi apostando nessa segunda hipótese que, neste primeiro atendimento, a conduta clínica adotada foi a de insistir para que ela brincasse, fazendo um novo convite para ela, ao invés de acatar a sua proposição de mudar de sala para a realização de uma conversa "adulta". Entende-se que esse manejo clínico foi arriscado, pois, caso a recusa em brincar fosse uma expressão do verdadeiro self de Lis, ela poderia brincar por se sentir cobrada pela estagiária a fazer algo que ela não queria, experienciando aspectos de submissão, que lembram o falso self durante o brincar (Pinéa \& Sei, 2015). Mas parece que essa manobra clínica se mostrou acertada, uma vez que, mediante o novo convite para brincar, ela se lançou a ele, chegando inclusive a pedir para brincar mais, ao final do primeiro encontro. Neste sentido, pode-se pensar que, caso a estagiária tivesse aceitado a proposta de Lis de obter o seu depoimento em outra sala, muito provavelmente o objetivo de produção de prova material teria sido alcançado já nesse primeiro momento da primeira entrevista, mas talvez a narrativa se desse de modo pouco integrado, vale dizer, com Lis assumindo uma postura defensiva e falsamente madura, o que poderia dar margem para uma nova vitimização.

Assim, compreende-se que, no contexto da escuta especializada, ao invés do profissional apressar-se em obter logo o depoimento da criança, mesmo que ela aparentasse estar disponível para tal, a "pressa" deve ser a de criar um bom vínculo com ela (o que pode se dar ou não através do brincar), para que só em momento posterior ela seja solicitada a prestar o seu depoimento. Essa premissa é importante diante da constatação de que nem sempre, no primeiro contato, a vítima já tem uma relação de confiança com o entrevistador a ponto de já conseguir relatar a violência sexual (Habigzang, Koller, Stroeher, Hatzenberger, \& Ramos, 2008), constatação essa que fica maximizada quando se trata de um incesto, que tende a ser atravessado pelo campo do segredo, com a criança demandando o seu próprio tempo para conseguir compartilhar o que lhe era tão secreto (Spagiari, Salvador, Barbeiro, \& Reis, 2020).

É válido ressaltar que, apesar de ficar combinado que, naquele primeiro momento, o depoimento seria deixado de lado, em detrimento do brincar, paradoxalmente, sem que fosse dirigida nesse sentido, Lis optou por um brincar que apresentava componentes relacionados intimamente com a história da violência sexual. Assim, a despeito de aqui estar sendo empregada artificialmente uma distinção entre o que seria uma conversa "adulta" e um momento lúdico, é claro que, na prática, essa separação não ocorre deste modo. Ao contrário, Lis fez uso do brincar não diretivo para comunicar justamente conteúdos da violência intrafamiliar. 
Ocorre que essa comunicação lúdica acaba impondo que o profissional tenha a capacidade de escutá-la de forma intuitiva, momentaneamente identificando-se com a criança, apartando-se de um pensamento mais concreto. Caso contrário, ele corre o risco de entender, de forma simplista e equivocada, que, no caso de Lis, por exemplo, ela estaria comunicando literalmente que quem abusara sexualmente dela fora o seu primo. Neste caso específico, entende-se que, através do brincar da família de patinhos, Lis comunicou a sua necessidade primeira de ilusoriamente fazer de conta que seu pai seria uma figura heroica, diferentemente do personagem do primo, em cima de quem foram depositados, de modo deslocado, os conteúdos destrutivos do pai. Só num segundo momento, após o encerramento dessa brincadeira com os patinhos, foi que Lis, já apta a se desiludir deste faz-deconta, conseguiu falar sobre a sua verdadeira história, em um percurso psíquico altamente complexo.

Essa necessidade de a criança vítima de violência intrafamiliar brincar de fazer de conta que advém de um lar protegido foi igualmente notada no estudo de Pedroso, Lobato e Magalhães (2016), que realizaram entrevistas com crianças acolhidas institucionalmente. A partir da observação de seu brincar, os autores notaram que havia uma tentativa de fugir da atual realidade, com as crianças fazendo uso do brincar para valorizar o imaginário, em detrimento do realismo.

Seria justamente porque, no brincar, há a possibilidade de transcender a realidade, com a atividade imaginativa sendo tão favorecida, que, no campo judicial, haveria a compreensão de que a comunicação lúdica seria questionável, duvidosa, com conotação de falsidade (Rodrigues, 2016). Se, por um lado, essa preocupação dos operadores do Direito com o brincar faz algum sentido, uma vez que estão acostumados a uma escuta reduzida apenas ao acontecimento factual, por outro lado, ela tampouco se sustenta, ao serem retomadas as pontuações de Winnicott (1971/1975) sobre o espaço potencial que pode vir a ser constituído durante o brincar. Para ele, nesse espaço intermediário, haveria tanto aspectos do mundo do eu quanto do mundo do não eu; em outras palavras, durante o brincar, a criança se movimenta dinamicamente entre esses dois lugares, havendo desse modo, seguramente, componentes de realidade partilhada coexistindo com conteúdos de cunho mais ilusório.

O brincar, na escuta especializada de Lis, revelou-se profícuo não apenas no primeiro encontro, como também no segundo, em que ela narrou a violência sexual tal como ocorreu. Vale destacar, em especial, o momento em que Lis declara sofrimento por ter que crescer com o ocorrido, e, logo em seguida, diante do impasse no jogo de dominó, inventa uma regra para que o jogo não tenha que acabar e as peças restantes ainda possam ser utilizadas. Em outras palavras, ao mesmo tempo em que a paciente comunicava verbalmente o seu sofrimento de ter que seguir adiante convivendo com a violência sexual cometida por seu pai, ludicamente expressou criatividade e força para fazer frente ao jogo de dominó, não aceitando que ele acabasse daquele jeito. Neste sentido, é possível levantar a dúvida: será que o fato de Lis e a estagiária estarem brincando, enquanto Lis 
relatava a violência sexual, não favoreceu para que ela pudesse expressar também a sua força psíquica?

Mediante o exposto, mais do que limitar a dúvida se o brincar é ou não válido, cabe ampliá-la para um questionamento maior: será que a resistência dos profissionais em relação ao uso do brincar, no momento em que a criança está apresentando o seu depoimento, não repousa num imaginário social de que o testemunho da criança seria fantasioso e frágil (Eloy, 2012)? E que só seria possível legitimar o seu depoimento se ela o fizesse de modo mais similar ao de um adulto, recorrendo apenas à comunicação verbal? Desde esta perspectiva, será que parte da rede de proteção não estaria, sem se dar conta, reproduzindo a histórica postura de desvalorização em relação à criança?

\section{AMAR OU ODIAR: EIS A QUESTÃO}

O segundo aspecto central, a ser debatido a partir da narrativa apresentada, referese à ambivalência afetiva apresentada por Lis, em relação a seu pai. Apesar de Lis ter comunicado verbalmente, nas duas entrevistas, que sentia raiva de seu pai e que, inclusive, desejava que ele morresse, pode-se pensar que ela também teria expressado, de modo não verbal, que sentia falta dele. Isso fica bem evidente, por exemplo, no primeiro atendimento, quando, logo após afirmar que não tinha mais notícias de seu pai, inclusive porque ela mesma não queria mais falar com ele, Lis propõe a brincadeira do telefone sem fio, que é uma brincadeira que remete à tentativa de se comunicar com alguém. Seria possível pensar que, nessa hora, a paciente também estivesse comunicando de modo tortuoso, tal como num telefone sem fio, que, ao mesmo tempo em que não queria, ela também queria poder se comunicar com ele?

É possível elucubrar que Lis também expressa não verbalmente a sua ambivalência afetiva, em relação ao pai, no final do segundo atendimento, quando pede para que o desenho seja dividido em duas partes, nomeando uma parte de bonita e a outra de feia. Será que esse movimento espontâneo de discriminar o bonito do feio poderia ser compreendido como uma tentativa da criança de se reorganizar psiquicamente, desmembrando o mesmo objeto em aspectos positivos e aspectos negativos? Seria possível pensar que Lis, que até então se relacionara com o seu pai por inteiro, levando em consideração seus aspectos amorosos e destrutivos, estivesse sendo convocada a enterrar a sua ambivalência afetiva para com ele, tendo que passar a apenas odiá-lo, sem jamais amá-lo?

Importa ressaltar esse aspecto, pois, comumente, na literatura especializada, tem sido debatida a problemática da ambivalência em relação ao agressor sexual da criança, mas desde a perspectiva da mãe da criança vitimizada. Trata-se de estudos valiosos, uma vez que de fato a mãe ocupa uma posição central nos casos de violência sexual intrafamiliar, podendo tanto interrompê-la quanto mantê-la, a depender de suas ações frente à revelação (Sufredini, Moré, \& Krenkel, 2016). Tais investigações mostram-se imprescindíveis inclusive porque têm viabilizado a percepção sofisticada de que a ambivalência materna estaria fundada não apenas 
em uma mera postura negligente por parte da mulher, como se pensava outrora, mas, sobretudo, num imaginário social patriarcal em que é previsto que a mulher assuma uma postura de submissão para manter a coesão familiar (Cunha \& Dutra, 2019).

Entretanto, no caso clínico de Lis, não era a mãe, e sim a criança, que parecia nutrir sentimentos ambivalentes. Trata-se de algo que foi igualmente observado no estudo de Martins (2015), que acompanhou um caso clínico em que a criança, após dois anos sofrendo violência sexual por parte do pai, fez a revelação para a mãe. Foi observado que, ao invés da criança se sentir aliviada, sentia-se profundamente angustiada, denotando que revelar pode às vezes ser mais difícil do que a própria experiência da violência sexual. Neste sentido, nota-se a importância da rede de proteção ser capaz de acolher os sentimentos ambivalentes que a criança pode vir a nutrir pelo agressor, não exigindo que ela apenas sustente sentimentos hostis em relação a ele.

Esta é uma questão importante de ser debatida, uma vez que, diante do quadro de violência sexual infantil, não raro os profissionais são contratransferencialmente atravessados pelo sentimento de revolta, em relação ao agressor, sustentando um horror e um clamor pela punição (Rodrigues, 2016). E, por vezes, preocupados em punir o agressor, principalmente nesse contexto da escuta especializada, em que há a intenção de produção material de prova para que the sejam aplicadas as medidas cabíveis, os profissionais podem não conseguir captar sensivelmente que a criança vitimizada ainda nutre sentimentos ambivalentes pelo agressor, não compartilhando de todo o ódio sustentado pelo entorno. Isso não significa, evidentemente, que o agressor deva deixar de ser punido; significa que se faz necessário levar em consideração a temporalidade emocional da criança vitimizada, que, por vezes, precisa experienciar um complexo processo de enlutamento.

Pode-se pensar, voltando ao caso de Lis, que talvez seja por isso que ela tenha começado a passar tão mal, quando foi integrada ao atendimento jurídico que estava sendo prestado à mãe dela, no final do segundo encontro. Porque, apesar da criança ter dito, em momento anterior, que gostaria que seu pai morresse, parece que se sentiu mal em ouvir que ele estava às vias de ser preso. É possível até levantar a dúvida se seu mal-estar decorreu do sentimento de culpa por ter deposto contra o seu pai, dando-se conta de que ela Ihe teria provocado algum dano, o que ambivalentemente ela desejava e não desejava.

Vale destacar que, apesar de, na narrativa, o mal-estar emocional de Lis, frente à punição do agressor, ter restado escancarado em relação ao atendimento prestado pela advogada, isso pode se dar mediante a atuação de quaisquer dos profissionais que compõem a rede de proteção, incluindo os profissionais da Psicologia, que podem acabar cometendo atuações contratransferenciais, pressionando a criança a assumir uma postura hostil frente ao agressor. Em autoexame mais cuidadoso, cabe questionar se, no momento em que a estagiária disse a Lis que ela poderia 
retirar o sobrenome de seu pai: 1) ela se sentiu mais autorizada a odiar o seu pai, sendo acolhida em sua revolta em relação a ele?; 2) ou, num extremo oposto, ela sentiu que deveria retirá-lo de sua vida, rompendo efetivamente com ele, assim como era aguardado por sua mãe e a advogada? Trata-se de uma questão complexa, que descortina a importância de, nos casos de violência sexual infantil, escutar as sutilezas da comunicação da criança, às vezes tão contraditória. Caso contrário, há o risco de os profissionais se relacionarem com a criança de modo também violento.

\section{CONSIDERAÇÕES FINAIS}

No presente trabalho, foi compartilhada uma das experiências clínicas em um ambulatório de violência sexual, no qual é realizada a escuta especializada. Vale destacar que, por vezes, sobrepor os dois objetivos - o de prestar cuidado à vítima, ao mesmo tempo em que se obtém o seu depoimento - não é possível, como nos casos em que a criança não se encontra em condições emocionais de compartilhar a narrativa da violência sexual sofrida, demandando dos profissionais da Psicologia um manejo exclusivamente interventivo, sem finalidade investigativa, no sentido de produção de provas. Em outros casos, entretanto, como foi o caso de Lis, a realização desse enquadramento revela-se completamente viável, sendo favorecido pelo uso de estratégias lúdicas auxiliando a comunicação significativa da criança, bem como facilitando para que ela se sinta emocionalmente sustentada e capaz de resgatar a sua espontaneidade. É importante também, conforme discutido previamente, que o profissional tenha organizado, dentro de si, que, mesmo depondo contra o agressor, a criança pode vir a ser atravessada por sentimentos ambivalentes em relação a ele, sentimentos esses que devem ser também acolhidos.

Espera-se, a partir deste relato de experiência, fomentar a inquietante discussão que tem atravessado as diferentes categorias de profissionais que compõem a rede de proteção, sobre como promover uma escuta especializada, junto à criança vitimizada, conjugando precisão e cuidado. Afinal, nestas três últimas décadas desde a promulgação do ECA, houve grandes avanços; contudo, dada a complexidade do fenômeno que é a violência sexual intrafamiliar, as atuações profissionais junto a esse público tão vulnerável seguem demandando maior amadurecimento.

\section{REFERÊNCIAS}

Benia, L. R. (2015). A entrevista com crianças com suspeita de abuso sexual. Estudos de Psicologia, 32(1), 27-35. https://doi.org/10.1590/0103-166X2015000100003

Cezar, P. K., \& Arpini, D. M., \& Goetz, E. R. (2017). Registros de notificação compulsória de violência envolvendo crianças e adolescentes. Psicologia: Ciência e Profissão, 37(2), 432-445. https://doi.org/10.1590/1982-3703001942015

Cunha, G. G., \& Dutra, E. M. do S. (2019). Um olhar fenomenológico para mães de crianças vítimas de abuso sexual: Uma revisão da literatura. Phenomenological Studies - Revista de Abordagem Gestáltica, 25 (1), 103-110. http://dx.doi.org/10.18065/RAG.2019v25.10 
Eloy, C. B. (2012). A credibilidade do testemunho da criança vítima de abuso sexual no contexto judiciário. Psicologia: Ciência e Profissão, 32(1), 234-249. http://dx.doi.org/10.1590/S141498932012000100017

Garbin, C. A. S., Queiroz, A. P. D., Rovida, T. A. S., \& Saliba, O. (2012). A violência familiar sofrida na infância: Uma investigação com adolescentes. Psicologia em Revista, 18(1), 107-118. https://doi.org/10.5752/P.1678-9563.2012v18n1p107

Giacomello, K. J., \& Melo, L. de L. (2011). Do faz de conta à realidade: Compreendend o o brincar de crianças institucionalizadas vítimas de violência por meio do brinquedo terapêutico. Ciência \& Saúde Coletiva, 16(1), 1571-1580. https://doi.org/10.1590/S1413-81232011000700093

Gomes, M. M. (2018). Discurso jurídico sobre a violência sexual à luz da psicanálise e da criminologia crítica: A presença da subjetividade nas ações jurídicas dos operadores do Direito. (Tese de Doutorado). Universidade Federal de Santa Catarina, Florianópolis.

Habigzang, L. F., Koller, S. H., Stroeher, F. H., Hatzen berger, R., \& Ramos, M. da S. (2008). Entrevista clínica com crianças e adolescentes vítimas de abuso sexual. Estudos de Psicologia, 13(3), 285-292. http://dx.doi.org/10.1590/S1413-294X2008000300011

Henriques, C. G. P., \& Pompeu, J. C. (2020). Sugestionabilidade e depoimento infantil: Protocolos de entrevista para minimização de falsas memórias. Diálogos interdisciplinares, 9(2), 1-12. Recuperado de https://revistas.brazcubas.br/index.php/dialogos/article/view/908

Martins, J. da M. (2015). O abuso sexual intrafamiliar: Do segredo à elaboração (Dissertação de Mestrado). Universidade Católica de Pernambuco, Recife.

Mendes, S. de F. (2019). Depoimento especial da criança e adolescente e produção da prova nos casos de violência sexual: Uma análise a partir da ecologia de saberes (Tese de Doutorado). Universidade Estadual de Ponta Grossa, Ponta Grossa.

Oliveira, D. C. C. de, \& Russo, J. A. (2017). Abuso sexual infantil em laudos psicológicos: As "duas psicologias". Physis Revista de Saúde Coletiva, 27(3), 579-604. https://doi.org/10.1590/S0103-73312017000300011

Pedroso, J. da S., Lobato, C. P., \& Magalhães, C. M. C. (2016). Brincar e realidade: Verbalizações de crianças em situação de acolhimento institucional. Psicologia em Estudo, 21(4), 711-721. https://doi.org/10.4025/psicolestud.v21i4.31806

Pinéa, A. C. F., \& Sei, M. B. (2015). Falso self e gesto espontâneo na psicoterapia psicanalítica de uma criança adotiva. Revista Brasileira de Psicoterapia, 17(1), 69-82. Recuperado de https://rbp.celg.org.br/detalhe_artigo.asp?id=170

Rocha, P. K., \& Prado, M. L. do (2006). Violência infantil e brinquedo terapêutico. Revista Gaúcha de Enfermagem, 27(3), 463-471. Recuperado de https://seer.ufrgs.br/RevistaGauchadeEnfermagem/article/view/4667/2583

Rodrigues, S. de M. (2016). A fantasia como realidade do sujeito: Uma leitura psicanalítica a partir do trabalho do psicólogo com crianças em situação de violência sexual (Dissertação de Mestrado). Universidade Federal do Maranhão, São Luís.

Sistema de Informação de Proteção para a Infância e Adolescência. (2019). Dados sobre a prática de violência sexual contra crianças e adolescentes.

Spagiari, N. T. B., Salvador, I. N., Barbeiro, F. de S., \& Reis, M. E. B. T. dos. (2020). O segredo despido pelo brincar na clínica psicanalítica. Analytica, 9(16), 1-19. Recuperado de http://www.seer.ufsj.edu.br/index.php/analytica/article/view/3003/2387

Sufredini, F., Moré, C. L. O. O., \& Krenkel, S. (2016). Abuso sexual infanto-juvenil na perspectiva das mães: Uma revisão sistemática. Contextos Clínicos, 9(2), 265-278. https://doi.org/10.4013/ctc.2016.92.11

Veloso, M. M. X., Magalhães, C. M. C., \& Cabral, I. R. (2017). Identificação e notificação de violência contra crianças e adolescentes: Limites e possibilidades de atuação de profissionais de saúde. Mudanças - Psicologia da Saúde, 25(1), 1-8. https://doi.org/10.15603/21761019/mud.v25n1p1-8

Winnicott, D. W. (1975). O brincar: Uma exposição teórica. Em D. W. Winnicott (Ed.), O brincar e a realidade (pp. 59-77). Rio de Janeiro, RJ: Imago editora. (Trabalho original publicado em 1971).

Winnicott, D. W. (1983). Distorção do ego em termos de falso e verdadeiro self. Em D. W. Winnicott (Ed.), O ambiente e os processos de maturação: Estudos sobre a teoria do desenvolvimento emocional (pp.128-1139). Porto Alegre, RS: Artes Médicas. (Trabalho original publicado em 1960). 
Winnicott, D. W. (1983). Os objetivos do tratamento psicanalítico. Em D. W. Winnicott (Ed.), O ambiente e os processos de maturação: Estudos sobre a teoria do desenvolvimento emocional (pp.152-155). Porto Alegre, RS: Artes Médicas. (Trabalho original publicado em 1965).

\section{CONFLITOS DE INTERESSES}

Não há conflitos de interesses.

\section{SOBRE AS AUTORAS}

Miriam Tachibana é docente no Instituto de Psicologia da Universidade Federal de Uberlândia. É pósdoutora em Psicologia pela Universidade de São Paulo com estágio pós-doutoral na Université de Paris X - Nanterre.

E-mail: mirita@ufu.br

(D) https://orcid.org/0000-0002-2373-4491

Paula Carvalho Barbosa é graduada em Psicologia pela Universidade Federal de Uberlândia. E-mail: paulacarvalhobufu@gmail.com

(2) https://orcid.org/0000-0003-0010-6561

\footnotetext{
${ }^{1}$ Embora exista um protocolo, no ambulatório em questão, de que não deve haver mais de um caso sendo atendido na sala de brinquedos, devido à falta de infraestrutura, eventualmente há momentos em que uma dupla de profissional e criança adentra a sala, enquanto um atendimento já estava ocorrendo ali.
} 